\title{
PRODUÇÃO DE TEXTOS NA ESCOLA: UMA EXPERIÊNCIA DE FORMAÇÃO COM PROFESSORES TIMORENSES
}

\author{
Joice Eloi GUIMARÃES ${ }^{1}$ \\ Cleusa TODESCATTO ${ }^{2}$
}

\begin{abstract}
Resumo: Este trabalho apresenta uma experiência de formação de professores e futuros professores de Timor-Leste. Nesse país, a língua portuguesa figura, desde 2002, como língua oficial, juntamente com a língua tétum. Desde então se tornou obrigatório seu ensino nos ambientes escolares. Contudo, muitos professores não dominam essa língua e, portanto, apresentam dificuldades em realizar sua prática pedagógica. Na formação realizada, apresentamos a metodologia de trabalho com a produção de textos a partir dos gêneros do discurso (BAKHTIN, 2011). Os dados coletados para a presente pesquisa são os enunciados produzidos pelos 21 participantes dessa formação. A metodologia utilizada para análise teve como referência a teoria do dialogismo de Mikhail Bakhtin. Com base nessa teoria, elegemos como categorias para análise os conceitos de estilo linear e estilo pictórico, componentes da apropriação e citação do discurso de outrem. Podemos afirmar que, ainda sem um conhecimento claro sobre o conceito de gêneros, provavelmente resquício de uma educação pautada na gramática da língua, foi possível aos cursistas a compreensão do tema trabalhado durante o curso. Nossa afirmação está pautada na utilização, pelos cursistas, do estilo pictórico para citar o discurso de outrem: os professores ministrantes do curso.
\end{abstract}

Palavras-chave: Formação de professores. Produção textual. Gêneros discursivos. Língua portuguesa. Timor-Leste.

\footnotetext{
${ }^{1}$ HUFS - Hankuk University of Foreign Studies - Departamento de Estudos Brasileiros. Gyeonggi-Do Yongin-Si - Coreia do Sul. 17035 - joiceeg@hotmail.com

${ }^{2}$ SEMED - Secretaria Municipal de Educação - Departamento de Gestão da Escola Básica Municipal Waldemar Pfeiffer. Concórdia - Santa Catarina - Brasil. 89705-268 - ctodescatto@hotmail.com 


\section{Introdução}

Em Timor-Leste, o trabalho com a Língua Portuguesa, doravante LP, nas escolas, precisa ser compreendido e pensado a partir de um ponto fundamental: os professores e os alunos timorenses envolvidos nos processos de ensino-aprendizagem realizados nesse país não são falantes nativos dessa língua. Ou seja, trata-se de uma prática pedagógica “com” e "sobre” uma língua não materna.

Dessa forma, as práticas com a LP em Timor-Leste configuram-se como desafio para professores/as e alunos/as, pois na maioria dos casos esses sujeitos apresentam dificuldades com essa língua. Sendo assim, em Timor, as discussões acerca do objeto e das metodologias para o ensino da LP precisam ser fundamentadas na sua característica de língua não materna. Além disso, no país, observamos, ainda, uma prática com a língua voltada, principalmente, aos aspectos estruturais, ao ensino da gramática. Dessa forma, acabam por serem deixadas de lado as práticas de linguagem - a oralidade, a escuta, a leitura e a produção de textos.

Diante dessa conjuntura, realizamos, na Universidade Nacional Timor-Lorosa'e (UNTL), um curso de formação para professores/as e futuros/as professores/as do ensino básico de Timor-Leste. Durante os cinco períodos do curso realizado com alunos/as do Departamento de Formação de Professores, contabilizando 20 horas, os/as cursistas puderam participar de estudos e discussões com aprofundamento de questões teóricas sobre a concepção de texto e os gêneros do discurso. Trocaram experiências com outros/as participantes, aprofundando reflexões sobre o ensino, especialmente no que se refere ao desenvolvimento de estratégias para a produção de textos na escola, ampliando, assim, o repertório de práticas de ensino de LP no contexto de timorense.

Em dois momentos distintos do curso, os/as participantes foram questionados acerca de suas experiências e expectativas em relação ao trabalho com a produção textual em suas aulas de LP. A pergunta inicial se deu no primeiro dia do curso e, a segunda, no último encontro. As respostas obtidas são nosso corpus de análise neste estudo. A partir desses enunciados, e com base na teoria do Dialogismo de Mikhail Bakhtin, analisamos de que forma a citação de outrem, seja de forma implícita ou explícita, revela posicionamentos ideológicos por parte dos sujeitos que participaram do referido curso. Para tanto, utilizamos como categorias de análise dois conceitos da teoria bakhtiniana: o 
de estilo linear, em que o locutor conserva, em seu enunciado, o discurso de outrem; e o de estilo pictórico, em que é possível perceber no enunciado do locutor suas respostas e seus comentários individuais acerca do discurso de outrem, apagando, dessa forma, as fronteiras entre os dois enunciados.

O presente artigo está organizado da seguinte forma: inicialmente faremos uma breve exposição acerca da LP e seu ensino em Timor-Leste. Em seguida, expomos a base teórica que orienta a metodologia que apresentamos aos cursistas: o trabalho com os textos na perspectiva dos gêneros. Após essa apresentação, serão discutidas as questões metodológicas e explicitados os procedimentos realizados na pesquisa e que possibilitam a análise dos dados, que será apresentada a seguir. Por fim, fazemos algumas considerações acerca dos enunciados analisados.

\section{A história da língua portuguesa em Timor-Leste}

No ano de 1512, chegaram em Timor-Leste os primeiros portugueses. Como em outros países desbravados, Timor tinha muitos recursos naturais a serem explorados e foi isso que aconteceu nesse país. Os portugueses investiram no “processo comercial com os nativos, negociando madeira e sândalo, entre outros produtos, em troca de roupas, armas e outros utensílios, até então desconhecidos desse grupo.” (TODESCATTO; SOARES, 2015, p. 108).

Em 1972, Portugal iniciou, de fato, o processo de colonização do povo timorense. Foram 162 anos de governo até que, no ano de 1864, Timor recebesse a sua independência governamental, sendo acolhido por Macau, que se tornou seu representante administrativo até o ano de 1889. Após esse período, Portugal voltou a administrar TimorLeste e, por conflitos internos, outra vez o país é abandonado pelo colonizador.

De 1942 a 1945, ocorreu a segunda invasão em Timor-Leste. Dessa vez, o vilão foi o Japão que, por interesses econômicos e geográficos, investiu fortemente na luta armada. Passada essa etapa, Timor ficou desamparado até o ano de 1974, quando a vizinha Indonésia invadiu o país, iniciando longos 24 anos (1975-1999) de opressão, mortes e uma forte imposição linguística, que faz da bahasa indonésia uma das línguas mais faladas pelos timorenses na atualidade. Isso porque no período de tomada do país, a Indonésia “entrou com todo o aparato de mídia de massa, incluindo apresentação e filmes, 
exibições, mídia impressa, rádio e televisão, sem mencionar a imposição de uma nova língua e de um novo conceito de estado ao povo timorense.” (GUNN, 2007, p. 50).

O massacre linguístico sofrido pelo povo timorense mostra-se ainda hoje em muitas das relações existentes entre Timor e Indonésia. A imposição da língua indonésia, juntamente com a proibição da LP foram, entre outras questões, elementos que demarcaram, profundamente, a intimidade entre esses dois povos.

A LP continuava a ser falada por alguns portugueses que continuaram em Timor e, no ano de 1983, a igreja católica criou o Externato São José, chamado posteriormente de escola portuguesa e, atualmente, de escola de referência.

Após o retorno dos jovens portugueses ao seu país, a escola continuou a ministrar cursos em LP. Porém no ano de 1992, após o massacre de Santa Cruz, que culminou na morte de centenas de jovens que se manifestaram pedindo a independência de Timor, as atividades na escola foram encerradas pelos militares, alegando que os seus estudantes haviam participado da "manifestação anti-Indonésia realizada durante a visita do Papa João Paulo II ao Timor-Leste em 1989 e também na manifestação/massacre no Cemitério de Santa Cruz”. (GUNN, 2007, p. 51).

Nesse episódio, um jornalista que acompanhava os acontecimentos no país filmou as cenas do ataque e as enviou para o exterior, o que permitiu, ao mundo, conhecer o que se passava em Timor. Com essas informações, a ONU (Organização das Nações Unidas) interviu promovendo debates entre os dois países envolvidos, com o intuito de resolver a situação e atender ao pedido de Timor-Leste: ter sua independência. No ano de 1999, enfim, o país se tornou independente, assumindo a Língua Portuguesa como língua oficial no ano de 2002.

Segundo Albuquerque (2010, p. 31),

\begin{abstract}
A língua portuguesa em Timor- Leste possui o status de língua oficial desde 2002, de acordo com a constituição da república, ao lado da língua nativa Tétum, em sua variedade Tétum-Praça. Duas outras línguas são previstas na constituição para serem utilizadas como línguas de trabalho, são elas: a língua inglesa e o bahasa indonésio.
\end{abstract}

Efetivando-se a Língua Portuguesa como língua oficial, em 2002, Timor iniciou um processo de projetos de cooperação com os países da CPLP (Conjunto de Países da 
Língua Portuguesa). Um dos objetivos foi implementar o ensino da LP nas escolas, iniciando com a formação de professores.

Os acordos econômicos com países que não falam a LP, muitas vezes, interferem negativamente para que essa língua seja falada pelos cidadãos timorenses, considerando a maior difusão de outras línguas, principalmente o inglês e a língua indonésia. Esse multilinguismo que norteia os rumos linguísticos de Timor torna-se um dos maiores desafios para o ensino-aprendizagem de uma das línguas oficiais, o português.

Diante de tantos obstáculos, faz-se necessária a preparação dos profissionais que atuam nas escolas, inclusive nos anos iniciais, no início do processo de ensinoaprendizagem da LP com crianças que ainda não tiveram contato com essa língua, exigindo-se, assim, eventos de formação continuada para esses professores que contemplem o conhecimento teórico e o metodológico da língua.

\section{O trabalho com o texto na perspectiva dos gêneros do discurso}

De acordo com Geraldi (1984), o trabalho com as práticas de linguagem oralidade, escuta, leitura e produção textual - na escola deve ter como ponto de partida o texto. Para esse autor, também a análise linguística deve ser ensinada e praticada tendo como base textos orais e escritos. Essa postura busca espaço nas práticas escolares, contrapondo-se ao conceito e emprego do texto que se fez historicamente nesse ambiente: como objeto de uso não de ensino; como suporte para as atividades de leitura e redação; como objeto de estudo de seus elementos estruturais; como pretexto para o ensino da gramática normativa e também da gramática textual (cf. ROJO; CORDEIRO, 2004).

A ineficiência dessas práticas aliada à constatação da heterogeneidade de textos existentes na sociedade e a quase inexistência deles nos ambientes escolares, bem como a desconsideração das circunstâncias de produção e leitura dos textos, levou a um redirecionamento no que diz respeito ao trabalho com o texto na sala de aula. "Trata-se então de enfocar, em sala de aula, o texto em seu funcionamento e em seu contexto de produção/leitura, evidenciando as significações geradas mais do que as propriedades formais que dão suporte a funcionamentos cognitivos.” (ROJO; CORDEIRO, 2004, p. 11). Nesse contexto e para dar conta dessa tarefa, autores interacionistas começam a ganhar destaque, dentre eles, o filósofo russo Mikhail Bakhtin. Para esse autor, a ordem metodológica para o estudo da linguagem deve partir de sua relação intrínseca com a vida, 
dos usos que os sujeitos fazem da linguagem nas situações de comunicação. Dessa forma, na concepção bakhtiniana, o texto (oral ou escrito) é considerado um conceito de importância fundamental, pois se constitui como a materialização dessa relação.

A constituição do homem social e da sua linguagem é mediada pelo texto; suas ideias e seus sentimentos se exprimem somente em forma de textos. Consequentemente, o acesso ao homem social e a sua linguagem se dá somente pela via do texto. (RODRIGUES, 2001, p. 69)

Essa premissa alicerça-se na concepção de linguagem como prática social que constitui e é constituída nas interações humanas, em diferentes gêneros do discurso. Os gêneros do discurso estão presentes na sociedade e, nessa perspectiva, toda a comunicação humana se dá através deles. É o uso do gênero nas relações sociais que determina sua existência. Ou seja, a produção dos gêneros é decorrente das produções discursivas, realizadas nas interações entre os sujeitos. Esse processo propicia a ocorrência de seu caminho inverso: quando estabelecidos socialmente, devido a sua utilização em situações de interação, os gêneros passam a influenciar a construção dos discursos, a escolha dos enunciados pelo falante, já que este o faz de acordo com a situação social de uso.

Os gêneros do discurso constituem-se, portanto, como produtos históricos e sociais que, no contínuo movimento da transitoriedade das ações humanas, estão sujeitos às mudanças decorrentes do contexto em que são produzidos.

A riqueza e a diversidade dos gêneros do discurso são infinitas porque são inesgotáveis as possibilidades da multiforme atividade humana e porque em cada campo dessa atividade é integral o repertório de gêneros do discurso, que cresce e se diferencia à medida que se desenvolve e se complexifica um determinado campo. (BAKHTIN, 2011, p. 262)

Compreender a complexidade do conceito de gênero na perspectiva de Bakhtin significa situar essas formas relativamente estáveis de enunciados no contínuo movimento histórico e social. Na esfera escolar, esse alcance tem relação direta com o processo de formação dos profissionais da área. Essa formação, em suas modalidades inicial e continuada, deve estar em diálogo constante com as inúmeras pesquisas 
desenvolvidas sobre o trabalho com os gêneros no espaço escolar, pois essas se fazem importantes à medida que geram contribuições na prática a que se referem.

Apesar de não ter voltado seus estudos para a esfera pedagógica, podemos, por meio das reflexões de Bakhtin, fazer apontamentos para essa área, inclusive para o ensino de uma língua não materna, pois, para o autor, o ensino de uma língua não materna deve seguir os mesmos princípios de ensino de uma língua materna: partir da língua em uso, inserida em um contexto e sendo constituída por ele.

O ponto de vista que defendemos, embora careça de uma sustentação teórica, constitui, na prática, a base de todos os métodos eficazes de ensino de línguas vivas estrangeiras. O essencial desses métodos é familiarizar o aprendiz com cada forma da língua inserida num contexto e numa situação concretas. Assim, uma palavra nova só é introduzida mediante uma série de contextos em que ela figure. [...] Em suma, um método eficaz e correto de ensino prático exige que a forma seja assimilada não no sistema abstrato da língua, isto é, como uma forma sempre idêntica a si mesma, mas na estrutura concreta da enunciação, como um signo flexível e variável. (BAKHTIN [VOLOCHÍNOV], 2010, p. 98).

Efetuada essa breve reflexão, cabe direcioná-la à realidade escolar de TimorLeste, buscando entender como se processam as reflexões teóricas em torno dos conteúdos a serem desenvolvidos na escola e como esta se apropria dos conceitos daí decorrentes e mesmo dos emanados das determinações oficiais - como a obrigatoriedade do ensino em LP no país.

Podemos supor que o desconhecimento dos/as professores/as em relação a essas teorias e metodologias é consequência, em parte, da ausência dessas perspectivas nos currículos do curso de Formação de Professores ${ }^{3}$, fato que favorece que esses sujeitos tenham dificuldades em se apropriar desse conteúdo. Sendo assim, consideramos como passo inicial, uma abertura para o diálogo e uma possibilidade de mudança nas práticas escolares de Timor, a formação realizada com os professores e futuros professores do ensino básico do país para o trabalho com os gêneros do discurso na escola.

\footnotetext{
${ }^{3}$ O currículo do curso de Licenciatura em Formação de Professores do Ensino Básico da Faculdade de Educação, Artes e Humanidades, Universidade Nacional Timor Lorosa'e (UNTL) compreende, em relação à língua portuguesa, as disciplinas de Língua Portuguesa I, II, III, IV e IV e Metodologia do Ensino da Língua Portuguesa. Nos conteúdos presentes nas fichas de Unidade Curricular dessas disciplinas, encontramos menção à prática de produção textual nas disciplinas de Língua Portuguesa II e IV, contudo sem especificar de que forma esse conteúdo é trabalhado. Na disciplina de Metodologia do Ensino da Língua Portuguesa são citadas, entre os conteúdos, as práticas de ouvir, falar e escrever no ensino básico.
} 


\section{Metodologia}

A tese central nos estudos realizados por Bakhtin e demais integrantes do Círculo de Bakhtin é de que a linguagem é dialógica. Nessa orientação teórica, o sujeito é tido como inacabado, sua constituição se dá nas interações, nas relações com o outro. Nessas relações, o interlocutor tem papel peculiar e distinto, essencial para que o diálogo seja acontecimento. Bakhtin (2011) afirma que a alteridade - o reconhecimento de si pelo outro - define o sujeito, sua formação ideológica, pois é impossível pensar o homem social fora das relações dialógicas das quais ele é partícipe. Nas palavras do autor,

\footnotetext{
A vida é dialógica por natureza. Viver significa participar do diálogo: interrogar ouvir, responder, concordar, etc. Nesse diálogo o homem participa inteiro e com toda a vida: com os olhos, os lábios, as mãos, a alma, o espírito, todo o corpo, os atos. Aplica-se totalmente na palavra, e essa palavra entra no tecido dialógico da vida humana, no simpósio universal. (BAKHTIN, 2011, p. 348)
}

Dessa forma, segundo Bakhtin [Volochínov] (2010), no horizonte da produção de qualquer enunciado encontra-se um interlocutor, o outro a quem a palavra se dirige. A posição do interlocutor, contudo, não se resume à de mero receptor da palavra de outrem. Todo interlocutor ocupa, em relação à palavra que lhe é dirigida, uma posição ativa, respondente, diante da palavra enunciada e a valora. A noção de compreensão ativa na perspectiva de Bakhtin está intrinsecamente ligada à resposta. Para esse autor, "O discurso como que vive na fronteira do seu próprio contexto e daquele de outrem.” (BAKHTIN, 2002, p. 91-92). Entendemos, portanto, a razão da tese de Bakhtin (2011), de que a compreensão (ativa) passa pela observância das relações entre sujeitos sociais, dado que estas são acontecimentos dialógicos.

Sendo assim, as respostas dos sujeitos às palavras do outro são elaboradas dialogicamente, na esfera da alteridade: são contra palavras às palavras de outrem. Contudo, a recepção do enunciado de outrem e sua transmissão em um contexto específico são processos distintos e que se inter-relacionam (BAKHTIN, 2010). O modo como o discurso de outrem é apropriado pelo sujeito é determinado pelo destinatário, o outro a quem a palavra é transmitida, ou seja, 
[...] a transmissão leva em conta uma terceira pessoa - a pessoa a quem estão sendo transmitidas as enunciações citadas. Essa orientação para uma terceira pessoa é de primordial importância: ela reforça a influência das forças sociais organizadas sobre o modo de apreensão do discurso. (BAKHTIN [VOLOCHÍNOV], 2010, p. 152)

Em conformidade com essa abordagem teórico-metodológica, é importante, nesta pesquisa, em que buscamos analisar a maneira como se dá a transmissão do discurso de outrem nos enunciados produzidos pelos/as 21 participantes do curso, professores/as ${ }^{4}$ e futuros/as professores/as ${ }^{5}$, ressaltar que o interlocutor, as docentes, ministrantes do curso, ocupam, historicamente, uma posição hierárquica no contexto de sala de aula. Conforme Bakhtin [Volochínov] (2010, p. 159), “Quanto mais forte for o sentimento de eminência hierárquica na enunciação de outrem, mais claramente definidas serão as suas fronteiras, e menos acessível será a ela a penetração por tendências exteriores de réplica e comentário.”. Ou seja, a posição que o/a docente ocupa está compreendida naquilo que Bakhtin anteriormente denomina de “forças sociais” que influenciam os modos de apreensão e transmissão do discurso.

Nossa análise recai sobre os enunciados produzidos em dois momentos distintos do curso de formação: no início do primeiro dia de curso e, após os 5 dias de discussões e práticas, no dia do encerramento. No primeiro momento, o/a cursista produz seu enunciado tendo no horizonte de produção as professoras, ministrantes do curso. Essa posição de interlocutor, conforme Bakhtin (2010) é elemento que compõe a produção do enunciado. No segundo momento, somado a isso, há a apropriação do discurso desse interlocutor e também do enunciado anteriormente escrito pelo próprio cursista, ou seja, o enunciado agora é produzido dialogicamente com o discurso do professor e o do próprio sujeito - que já não é o mesmo, visto que a situação social é outra, situação essa que se entrelaça na produção desses enunciados desde seu interior.

As duas perguntas que fizemos aos/às participantes do curso foram as seguintes:

\footnotetext{
${ }^{4}$ Alunos da Classe de Extensão. Esse curso integra o departamento de Formação de Professores da Faculdade de Educação, Artes e Humanidades (FEAH) da Universidade Nacional de Timor-Lorosa'e. Com $90 \%$ de disciplinas correspondentes às presentes no currículo do curso de Formação de Professores, destinase a professores atuantes nas escolas do país, mas que não possuem, ainda, formação de nível superior.

${ }^{5}$ Graduandos do Curso de Formação de Professores do Departamento de Formação de Professores da Faculdade de Educação, Artes e Humanidades da Universidade Nacional de Timor-Leste.
} 
Em uma aula de Língua Portuguesa, que texto você pediria para seus alunos escreverem? De que forma realizaria essa atividade? (primeiro momento) ${ }^{6}$.

Em relação a sua proposta inicial para a produção de textos (aquela que você descreveu no primeiro dia desse curso), você faria alguma mudança? Qual? Por quê? (segundo momento) ${ }^{7}$.

Os enunciados produzidos como respostas a essas questões serão analisados tendo em vista as estratégias empregadas na reprodução do discurso de outrem, as quais representam uma tomada de posição do sujeito que enuncia, aproximando-se ou afastando-se do discurso que cita ou, ainda, apagando-o.

Bakhtin [Volochinov] (2010) indica duas orientações de citação a partir da relação entre o locutor e o discurso de outrem que ele cita. A primeira, o estilo linear, corresponde à criação de contornos exteriores ao redor da voz alheia que o locutor cita. "Nesse caso, os esquemas linguísticos e suas variantes têm a função de isolar mais clara e mais estritamente o discurso citado, de protegê-lo de infiltração pelas entoações próprias do autor, de simplificar e consolidar suas características linguísticas individuais.” (BAKHTIN [VOLOCHÍNOV], 2010, p. 155). Na segunda orientação, o estilo pictórico, o locutor infiltra, sutilmente, seus comentários no discurso do outro. Dessa forma, "Sua tendência é atenuar os contornos exteriores nítidos da palavra de outrem.” (BAKHTIN [VOLOCHÍNOV], 2010, p. 156-157). Nesse caso, há uma diluição dos limites existentes entre os dois discursos. As fronteiras entre o discurso citado e o discurso de outrem são apagadas.

Por meio desses conceitos, apresentamos, na seção seguinte, a análise dos enunciados dos participantes desta pesquisa, buscando compreender o modo como esses sujeitos, na produção de seus enunciados, se apropriam e transmitem os enunciados proferidos pelos ministrantes do curso e aqueles produzidos por eles próprios.

\section{Análise dos dados}

As respostas obtidas à primeira questão são apresentadas abaixo. Na Tabela 1 , elencamos as respostas dos participantes do curso que ainda não atuam em sala de aula e,

\footnotetext{
${ }^{6}$ Essa pergunta foi respondida por 21 participantes.

${ }^{7}$ Essa pergunta foi respondida por 16 participantes.
} 
na Tabela 2, as respostas dos cursistas que atuam como professores do ensino básico. Nesse primeiro momento, realizamos apenas a exposição desses dados para, no segundo momento, utilizá-los como contra palavra aos enunciados produzidos como resposta à segunda questão, aplicada no último dia de curso. Vale lembrar que, na análise do conjunto dos enunciados, são levados em conta também os discursos dos professores ministrantes do curso, pois partimos do pressuposto de que esses discursos integraram a produção dos enunciados dos cursistas.

Tabela 1: Dados dos cursistas que não atuam em sala de aula (13)

\begin{tabular}{|c|c|c|c|}
\hline Gêneros textuais & Quantidade & Metodologia & Quantidade \\
\hline Fábula & 1 & Interpretação do texto & 5 \\
\hline Mitos & 1 & Leitura & 1 \\
\hline Lendas & 2 & Contar histórias & 1 \\
\hline & & Produção textual: Individual & 3 \\
& & Em grupo & 1 \\
\hline
\end{tabular}

Observamos que apenas três gêneros textuais foram citados, o que atesta, em parte, nossa hipótese de que a maioria dos alunos não distingue gênero textual e tipologia textual. Algumas respostas (9) se referiram apenas à temática sugerida para a produção do texto e não ao gênero e 3 cursistas não mencionaram em suas respostas nem o gênero nem o tema, apenas a produção de “textos diversos”.

Em relação à metodologia utilizada em suas atividades em sala de aula, nem um dos estudantes especificou o como realizaria a prática de produção textual. Consideramos que isso se deva ao fato de os alunos ainda não terem vivenciado a prática de sala de aula, apenas a teoria que remete à metodologia de ensino, como pode ser visto nos enunciados: “Criar um currículo e adaptar os métodos de ensino” e “Método experimental”. Algumas das atividades apresentadas como resposta a essa questão, pautam-se, principalmente, na estrutura textual e linguística: ensinar parágrafo (2); explicação da estrutura do texto introdução, desenvolvimento e conclusão - (5); orações (1); pontuação (1); tipos de frases (1).

Em relação aos professores atuantes em sala de aula, apresentamos abaixo um quantitativo de suas respostas: 
Tabela 2: Dados dos cursistas que já atuam em sala de aula (8)

\begin{tabular}{|l|c|c|c|}
\hline Gêneros Textuais & Quantidade & Metodologia & Quantidade \\
\hline Não foram citados & 0 & $\begin{array}{c}\text { Explicação da matéria trabalhada } \\
\text { no dia }\end{array}$ & 6 \\
\hline & & O aluno ler o texto dado & 5 \\
\hline & & Interpretação de texto & 5 \\
\hline & & $\begin{array}{c}\text { Explicação da temática referente } \\
\text { ao texto }\end{array}$ & 4 \\
\hline & & Desenho sobre o texto & 3 \\
\hline & & Pintar & 3 \\
\hline & & Produção textual & 2 \\
\hline & & $\begin{array}{c}\text { Explicação da matéria do dia } \\
\text { anterior }\end{array}$ & 1 \\
\hline & & Cantar & 1 \\
\hline & & Exercícios de fixação & 1 \\
\hline
\end{tabular}

Nos dados obtidos, chama a atenção que os/as professores/as não citaram em suas respostas nenhum gênero específico para a produção dos textos. Em se tratando da metodologia, vemos que esses sujeitos aparentam ter mais conhecimento desse tema que os alunos que ainda não atuam em sala. Contudo, observamos que há uma confusão entre o que é conteúdo e o que é metodologia e, ainda, o que é sequência didática. Alguns conteúdos foram tratados como metodologia, por exemplo: o estudo e reconhecimento das letras (1). Um número de 4 professores citou apenas como metodologia "preparar o texto”.

\section{O discurso de outrem nos enunciados dos cursistas}

Como afirma Bakhtin [Volochínov] (2010), os enunciados que produzimos são eventos únicos e irrepetíveis, contudo são constituídos e carregam sempre as marcas de enunciados de outrem. A forma como se dá a assimilação e transmissão desse discurso define o estilo da citação. Esse processo pode ocorrer de maneira clara e com fronteiras bem demarcadas entre os dois discursos (estilo linear), ou com a presença de marcas da subjetividade daquele que enuncia o discurso citado (estilo pictórico).

Sabemos que o mecanismo do discurso citado assume funções distintas conforme o gênero em que os enunciados são produzidos. No caso desta pesquisa, as questões requeriam como resposta textos de opinião. Conforme Bakhtin (2011), os gêneros são 
relativamente estáveis com base nas condições específicas e nas finalidades de cada uma das esferas da atividade humana. O gênero “texto de opinião” tem como principal objetivo expor um determinado ponto de vista e defendê-lo, buscando convencer o leitor daquilo que é exposto. Em se tratando de um gênero em que predomina a tipologia textual argumentativa, o locutor pode buscar legitimar seu ponto de vista introduzindo, na construção do seu discurso, a voz de outros enunciados.

Observamos que a maioria dos/as participantes desta pesquisa, como resposta à segunda questão, citaram em seus enunciados os discursos produzidos pelos ministrantes do curso, ou seja, há uma presença recorrente de marcas do discurso do professor. A posição hierárquica que o docente ocupa, na situação de sala de aula, agrega ao seu enunciado um caráter de verdade, o qual é apropriado ao discurso do cursista como argumento que endossa seu ponto de vista. Conforme Bakhtin [Volochínov] (2010, p. 156), “Quanto mais dogmática for a palavra, menos apreensão apreciativa admitirá a passagem do verdadeiro ao falso, do bem ao mal e mais impessoais serão as formas de transmissão do discurso de outrem.”. A valoração do docente e os reflexos dela nos ambientes educativos nos mostram que as práticas sociais, nas quais os sujeitos estão inseridos, influenciam nas ideologias reveladas em seus discursos. Vejamos alguns exemplos de enunciados produzidos por um mesmo autor, como respostas à primeira e à segunda questões ${ }^{8}$ :

Resposta à questão 1: “[...] eu gostaria de pedir, os alunos escreveriam um texto sobre fábula, lendas e mitos porque esses textos são textos interessante para atrair os desejos dos alunos para aprender. E a maneira de realizar esses textos em primeiro precisaria de explicar como é que escrevemos bem uma texto, exemplo de fazer a introdução, o desenvolvimento e a conclusão. E uma coisa importante também é como é que os tipos das frases para colocar bem as pontuações nas frases.”

Resposta à questão 2:“[...] pedir os alunos à produzir um texto sobre o texto narrativo do gênero fabula, mitos, lendas e cantigas [...] porque como os alunos ainda na idade de criança o mais importante é dizer para os alunos a produzir um texto brincadeira ou conforme o ambiente que os alunos convívio [...] E como um professor no futuro não

\footnotetext{
${ }^{8}$ Os trechos foram transcritos conforme o original.
} 
poderei avaliar os alunos sobre as suas formas de frases, as suas produção de texto estruturada, uma coisa importante é avaliar e apreciar também o que os alunos expressam num texto.” (grifos nossos).

Entre os dois enunciados acima, percebemos que há uma negação do discurso anteriormente citado e uma assimilação do discurso das professoras. O termo gênero, por exemplo, aparece apenas no segundo trecho. Podemos inferir que a utilização desse termo tem relação direta com sua difusão nas discussões realizadas durante o curso. Outra relação direta que podemos estabelecer com o discurso das professoras ministrantes do curso é a referência que aparece, na segunda resposta, à importância de se ouvir o que o aluno tem a dizer e não apenas corrigir gramaticalmente seu texto. Em vários momentos do curso, houve a tentativa, por parte das ministrantes, de desconstruir a concepção de texto tendo como ponto de partida a gramática da língua. A proposta foi que o professor se colocasse como leitor da produção do aluno e não apenas como um corretor de aspectos gramaticais.

No trecho acima, vemos que os discursos foram citados sem que se fizesse referência à palavra de outrem - do professor, ou seja, foram introduzidos no discurso citado como parte de sua construção, configurando, conforme Bakhtin [Volochínov] (2010, p. 156-157, grifos do original), a ocorrência do estilo pictórico, em que “A língua elabora meios mais sutis e mais versáteis para permitir ao autor infiltrar suas réplicas e seus comentários no discurso de outrem. O contexto narrativo esforça-se por desfazer a estrutura compacta e fechada do discurso citado, por absolvê-lo e apagar as suas fronteiras.”.

Em seguida, apresentamos outro exemplo da presença do estilo pictórico nos discursos analisados. No primeiro trecho, o cursista apresenta o tema proposto para a produção textual e o considera suficiente para os alunos realizarem a atividade. Como resposta à segunda pergunta, observamos a presença de enunciados das ministrantes do curso em relação à importância da produção textual e também de estratégias metodológicas em meio ao enunciado do cursista. 
Resposta à questão 1: “[...] gostaria que dar o texto sobre “A minha família” para os alunos poderiam escrever e entender essa matéria. [...] utilizar o método de experimentais para os alunos pode tentar elaborar um texto muitas vezes até eles entenderem [...].”

Resposta à questão 2: “A produção de texto é essencial para os professores porque para tratar os assuntos adequados este texto, poderei de fazer: Definição do texto mostrar o fotografia, e os exemplos [...].” (grifos nossos)

Para Bakhtin [Volochínov] (2010, p. 153-154), a apreensão do discurso de outrem se dá de maneira ativa, pois “Aquele que apreende a enunciação de outrem não é um ser mudo, privado de palavra, mas ao contrário um ser cheio de palavras interiores.”. É por meio do discurso interior que ocorre a compreensão e a apreciação do discurso apreendido e, consequentemente, a réplica interior e o comentário efetivo. As expressões, A produção textual é essencial e poderei de fazer, contidas no enunciado acima, demonstram essas duas operações fundidas: o enunciado de outrem colocado no contexto do discurso e a presença da palavra daquele que a cita, sua réplica em relação ao discurso citado.

O último exemplo que trazemos cita, como resposta à segunda questão, diretamente o discurso do professor, o qual, por sua vez, utilizou também, por meio do estilo linear, Geraldi (1995), para quem o ato de escrever pressupõe: ter o que dizer; ter a quem dizer; ter razões para dizer; constituir-se enquanto locutor/sujeito do dizer e dispor dos mecanismos e estratégias do dizer.

Resposta à questão 1: “[...] Precisa le sobre objetivo do texto para o aluno depois explica para aluno para compreender sobre texto que professor ler. depois criar uma atividade que relaciona sobre textu por exemplo dividir as palavras ou perguntar sobre objetivo de textu."

Resposta à questão 2: “Tem mudança por que uma texto precisa saber objetivo por exemplo que texto é esse? para que esse texto? e depois para quem? ultimo como esse texto? Muda ideia sobre não basta saber falar e escrever mais precisa utilizar texto gramaticais e depois precisa conhecer tipo cada alunos.” (grifos nossos) 
Como resposta à segunda questão, percebemos que o cursista manifesta o discurso das professoras quando elenca as perguntas enfatizadas durante o curso, quando foram trabalhados os gêneros textuais e suas características e funções. Para tanto, utiliza o estilo pictórico. Ainda que o enunciado do/a aluno/a não revele que a fala foi recorrente durante o curso, ele/a manifesta claramente em seu comentário efetivo as proposições realizadas pelos professores.

Nos enunciados dos cursistas não nos foi possível perceber a ocorrência do estilo linear, que no gênero em questão, o texto de opinião, é um recurso argumentativo empregado com intuito de inserir enunciados que legitimem o ponto de vista defendido. Inferimos que essa não ocorrência esteja relacionada a alguns fatores específicos da situação de produção dos enunciados como o desconhecimento por parte dos cursistas dos temas trabalhados durante o curso, à predominância das discussões orais durante o curso e, principalmente, à característica de língua não materna da LP para os timorenses.

\section{Considerações}

A produção dos enunciados nas diferentes situações de comunicação está sempre em relação com outros enunciados, como resposta ou antecipação a eles. Ao enunciarmos, trazemos para nosso discurso as palavras de outrem. Somos por elas influenciados e, consequentemente, modificados.

No caso desta pesquisa, observamos que a tomada de posição dos sujeitos perante o tema sugerido para discussão foi direcionada pelo discurso de outrem, o das professoras ministrantes do curso. Esse redirecionamento ideológico foi percebido por meio da assimilação e citação do discurso das professoras que se deu, preponderantemente, por meio do estilo pictórico, pois os cursistas, como resposta à segunda questão, entrelaçaram à construção do seu discurso, sem demarcar claramente o discurso de outrem, o enunciado das docentes. Entre as razões para tanto, consideramos a posição hierárquica que o docente ocupa na situação de sala de aula, situação que percebemos mais claramente em Timor-Leste e, também, o gênero em que o enunciado é produzido, nesse caso um texto de opinião que não suscita diretamente a citação do discurso de outrem. Nesse sentido, vemos como as práticas sociais as quais os sujeitos estão inseridos influenciam nas ideologias reveladas em seus discursos. 
À ausência do estilo linear relacionamos ao reduzido número de timorenses que dominam a LP. Apesar da longa presença dessa língua em Timor-Leste, mesmo os professores que a ensinam apresentam muitas dificuldades de uso. Assim sendo, no caso dos enunciados analisados, podemos inferir que a dificuldade de cunho linguístico foi um fator que influenciou na maneira como esses sujeitos dialogaram com os enunciados das professoras ministrantes e os assimilaram aos seus discursos.

Vale ressaltar que apesar das dificuldades com a LP, os cursistas, na sua maioria, conseguiram compreender os temas abordados durante o curso. Essa percepção se dá pelas mudanças discursivas que sobressaíram nas respostas dadas à segunda questão, quando comparadas à primeira.

GUIMARÃES, Joice Eloi; TODESCATTO, Cleusa. Writing in school: a training experience with timorens teachers. Revista do Gel, v. 14, n. 1, p. 59-76, 2017.

Abstract: This paper presents an experience of work with teachers training and with future teachers of East Timor. In this country, the Portuguese Language figures, since 2002, as official language along with Tetum, another local language. Since then, teaching Portuguese Language became compulsory in their schools. However, many teachers do not master it and therefore they have difficulties in their pedagogical practice. In this training process, we presented a work methodology with writing based on the speech genres (BAKHTIN, 2011). The data collected for this research are statements made by the 21 participants in this process. The methodology used for the analysis had as reference the Bakhtin's dialogism theory. Based on this theory, we have chosen as categories for analysis the concepts of linear and pictorial style, components of the appropriation and quotation of another one's speech. We can say that, even without a clear understanding of the genres concept, probably because of an education based on the grammar of the language, it was possible for participants to understand the subject in question during the course. Our point is guided in the use, by participants, of the pictorial style to quote another one's speech: the teachers who are teaching in the course.

Keywords: Teachers training. Writing. Speech genres. Portuguese language. East Timor.

Submetido em: 08/04/2016.

Aceito em: 03/10/2016. 


\section{Referências}

ALBUQUERQUE, D. B. de. O ensino de Língua Portuguesa em Timor-Leste: variedades e dificuldades. Interdisciplinar. v. 12, p. 31-47, jul.-dez. 2010.

BAKHTIN, M. M. (V. N. Volochínov). Marxismo e filosofia da linguagem. 14. ed. São Paulo: Hucitec, 2010.

BAKHTIN, M. O discurso no romance. In: BAKHTIN, M. Questões de literatura e de estética. 5. ed. São Paulo: HUCITEC/ANNABLUME, 2002. p. 71-164.

Os gêneros do discurso. Estética da criação verbal. 6. ed. São Paulo: Martins Fontes, 2011. p. 261-306.

GERALDI, J. W. O texto na sala de aula: leitura e produção. Cascavel: ASSOESTE, 1984.

Portos de passagem. 3. ed. São Paulo: Martins Fontes, 1995.

GUNN, G. C. A ocupação Indonésia de Timor Leste: lições e legados para a construção do estado na nova nação. In: SIMIÃO, D. S.; SILVA, K. C. (Org.). Timor Leste por trás do palco - Cooperação internacional e a dialética da formação do estado. Belo Horizonte: Editora UFMG, 2007.

RODRIGUES, R. H. A constituição e o funcionamento do gênero jornalístico artigo: cronotopo e dialogismo. 2001. 347 f. Tese (Doutorado em Linguística Aplicada e Estudos da Linguagem) - Pontifícia Universidade Católica de São Paulo, São Paulo, 2001.

ROJO, R.; CORDEIRO, G. S. Apresentação. Gêneros orais e escritos como objetos de ensino: modo de pensar, modo de fazer. In: SCHNEUWLY, B.; DOLZ, J. Gêneros orais e escritos na escola. Tradução e organização de Roxane Rojo e Glaís Sales Cordeiro. Campinas: Mercado de Letras, 2004. p. 7-16.

TODESCATTO, C.; SOARES, F. S. Língua Portuguesa no Timor-Leste: uma língua da resistência. Revista Advérbio, v. 10, n. 20, p. 105-119, ago. 2015. 